\title{
Q fever is an old and neglected zoonotic disease in Kenya: a systematic review
}

\author{
J. Njeru ${ }^{1,2,3^{*}}$, K. Henning $^{1}$, M. W. Pletz ${ }^{2}$, R. Heller ${ }^{4}$ and H. Neubauer ${ }^{1}$
}

\begin{abstract}
Background: Q fever is a neglected zoonosis caused by the bacterium Coxiella burnetii. The knowledge of the epidemiology of $\mathrm{Q}$ fever in Kenya is limited with no attention to control and prevention programs. The purpose of this review is to understand the situation of $\mathrm{Q}$ fever in human and animal populations in Kenya in the past 60 years, and help identify future research priorities for the country.

Methods: Databases were searched for national and international scientific studies or reports on $\mathrm{Q}$ fever. We included studies and reports published between 1950 and 2015 if they reported on Q fever prevalence, incidence, and infection control programs in Kenya. Data were extracted with respect to studies on prevalence of Coxiella infections, study design, study region, the study populations involved, and sorted according to the year of the study.

Results: We identified 15 studies and reports which qualified for data extraction. Human seroprevalence studies revealed evidence of C. burnetii infections ranging from 3 to $35.8 \%$ in all regions in which surveys were made and two Q fever outbreak episodes. Coxiella burnetii infections found in cattle 7.4-51.1\%, sheep 6.7-20 \%, camels 20$46 \%$, and goats $20-46 \%$ revealed variation based on ecoregions and the year of study. Farming and lack of protective clothing were associated with increased seropositivity among humans. However, high quality data is lacking on Q fever awareness, underlying cultural-economic factors influencing C. burnetii infection, and how the pathogen cycles may be embedded in livestock production and management systems in the economically and ecologically different Kenyan regions. We found no studies on national disease incidence estimates or disease surveillance and control efforts.
\end{abstract}

Conclusion: Coxiella burnetii infections are common in human and in a wide range of animal populations but are still unrecognized and underestimated thus presenting a significant human and animal health threat in Kenya. The factors influencing pathogen transmission, persistence and spread are poorly understood. Integrated disease surveillance and prevention/control programs are needed in Kenya.

Keywords: Seroprevalence, Epidemiology, Coxiella burnetii, Q fever, Kenya

\section{Background}

$\mathrm{Q}$ fever is an acute (on occasion chronic) zoonotic disease of great public health importance worldwide. The disease is caused by an obligate gram-negative bacterium; Coxiella burnetii [1]. Coxiella (C). burnetii belongs to the genus Coxiella of the gamma subdivision of Proteobaccteria along with the genera Legionella,

\footnotetext{
* Correspondence: John.Njeru@fli.bund.de

${ }^{1}$ Institute of Bacterial Infections and Zoonosis, Friedrich-Loeffler-Institut, 07743 Jena, Germany

${ }^{2}$ Center for Infectious Diseases and Infection Control, Jena University

Hospital, 07740 Jena, Germany

Full list of author information is available at the end of the article
}

Francisella, and Rickettsiella. Unlike the other members of Proteobaccteria, C. burnetii is highly resistant to adverse physical conditions and chemical agents, so it can survive for months and even years in the environment. Its preferred target cells are macrophages located in body tissues and the monocytes circulating in the blood stream [2]. C. burnetii exists in two distinct antigenic forms, the phase I and phase II bacterial variants which can be discriminated by the surface lipopolysaccharide (LPS) composition. This antigenic variation is important for serological diagnosis and pathogenesis. Phase I variants are the highly infectious forms found in naturally 
infected hosts whereas phase II variants are less infectious and are obtained after serial passages in cell culture systems or embryonated eggs [3].

Domestic animals such as cattle, sheep and goats act as the major reservoirs of $C$. burnetii which can infect a large variety of animals, humans, birds, and arthropods [4-7]. Human infection results from inhalation of contaminated aerosols, consumption of contaminated unpasteurized dairy products, direct contact with contaminated milk, urine, feces, or semen of infected animals, and tick bites $[8,9]$. Clinical presentation is nonspecific and highly variable ranging from asymptomatic infection $(60 \%)$ or self-limiting febrile illness associated with fatigue, headache, general malaise, myalgia, arthralgia, to atypical pneumonia(rapidly progressive courses may occur) and/or hepatitis. Less frequent complications include endocarditis, osteomyelitis and aseptic meningitis. About 1-2 \% of acute symptomatic cases may develop chronic disease [10, 11]. Q fever is considered to be an occupational disease of people who have intimate contact with animals or their products such as veterinarians, farmers, abattoir workers, and laboratory workers [12]. There is emerging evidence of $C$. burnetii as a cause of non-malaria febrile illness and community acquired pneumonia in many developing countries [13-18], but hospital based diagnosis of $\mathrm{Q}$ fever in Kenya is uncommon. The lack of attention is mainly due to scarcity of available data and the perceived low clinical relevance of $\mathrm{Q}$ fever in relation to other endemic fevers. As a result, the disease might often be underreported and the disease burden grossly under-estimated [19].

In animals, $\mathrm{Q}$ fever is frequently asymptomatic. Sheep and goats may exhibit abortion, stillbirth, premature delivery, and delivery of weak offspring while cattle and camel may develop infertility, metritis, and mastitis [20, 21]. Animal studies have demonstrated that vaginal mucus, feces, and urine are the common shedding route and means for environmental contamination through kidding and effluent mismanagement $[22,23]$. Mammals also considerably shed C. burnetii in milk and thus consumption of contaminated unpasteurized milk or dairy products can be a significant source of human infection [24]. Similar to humans, Q fever is under appreciated as cause of animal disease in Kenya possibly leading to persistence of the infection in animal herds, impacting on livestock productivity, and acting as sources of infection for humans [15].

The epidemiology of Q fever in Kenya is poorly understood due the apparent neglect of the disease by both medical and veterinary personnel and the limited capacity to enable meaningful epidemiological surveys. Therefore, we reviewed the literatures on $\mathrm{Q}$ fever among human and animal populations in Kenya, from 1950 to 2015 to understand the epidemiological features of the disease. The study also hoped to derive appropriate lessons from the Kenyan situation, and to identify the existing knowledge gaps on the C. burnetii infections in humans and animals, and the disease control programs.

\section{Methods}

Search

Databases including CABDIRECT, Science Direct, PubMed, and Google scholar were used for the searches. Available unpublished reports and theses from Kenyan university libraries and government departments were systematically searched. Other related articles emerging during the searches were also considered as sources of additional information. The searched publications were reviewed and relevant information was retrieved. The following keywords were used to perform the searches: 'Coxiella in Kenya' 'Q fever in Kenya' 'Q fever in humans and animals in Kenya,' 'Coxiella in humans and animals in Kenya' and 'zoonotic diseases in Kenya'. Studies or articles were included if they provided information on Q fever/Coxiella burnetii prevalence, disease incidence or outbreak, and infection control programmes in Kenya. Bibliographies of selected papers were also reviewed and grey literature searches performed for additional information. The studies or reports with unrelated reports were then excluded. The collected studies were reviewed and classified based on the study group (animals, humans and arthropods) and sorted according to the year of the study. All studies in humans indicating either acute or chronic disease were included. The seropositivity was used to describe serologic reactions that met the recommended titer cut-offs of the respective test method used. The clinical disease status was reported if the test method used meets the present guidelines for case definition [25].

\section{Results \\ Data acquisition}

In this review, 15 articles including published papers, conference abstracts/posters, student theses and government reports were ultimately identified and reviewed. These included nine (9) studies on humans [26-34], four (4) on animals [35-38], two (2) on ticks [17, 39], and two (2) studies on both animals and humans $[17,29]$ (Fig. 1). These studies differed in the methodological designs such as sample size, method of sample selection and collection, diagnostic criteria, and had limitations associated with the small scale cross-sectional epidemiological studies. For instance, five of these reports were case studies; two were outbreak reports whilst three studies were retrospective sero-epidemiological studies. The latter utilized either banked sera collected or 


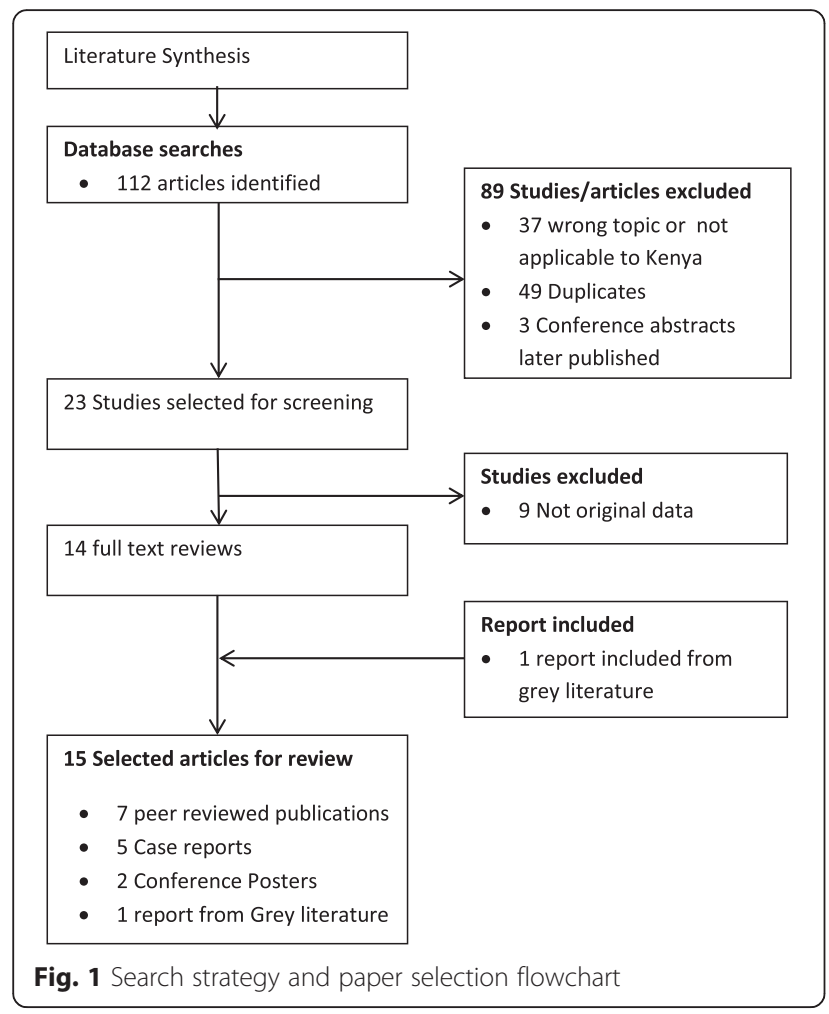

submitted to research laboratories or specialized hospitals for disease diagnosis and did not provide proof of random sampling, hence sampling bias may have been significant in these studies.

\section{Evolution of the number of publications}

The first publication of Q fever dates back to 1950s. The period from 1950 and 1976 was characterized by eight regional studies. This was then followed by a 32 year period (1971-2008) of no prevalence/incidence, except for an outbreak report documented in 2000. A slow increase of regional studies was found between 2008 and 2014 (Fig. 2).

\section{Disease attributed to $C$. burnetii in humans ( $Q$ fever)}

The first human case of Q fever was reported in 1952 in a human clinical case in Nairobi [26]. Between 1955 and 1956, 17 more patients admitted to hospitals in Nairobi and Nakuru towns were found to have $Q$ fever. These presented with febrile illness previously suspected and treated for viral pneumonia, malaria or other tropical fevers. Eventually, laboratory screening revealed that they were seropositive for $C$. burnetii. All these patients with exception of one were adult immigrants [27, 28]. A study conducted from 1967 to 1968 using archived sera obtained from hospitals in Western, Rift Valley, Central, Eastern, and Coast provinces of Kenya demonstrated an average seroprevalence of $35.8 \%$ [29]. In the study, $C$. burnetii antibodies were detected in samples from all the participating hospitals. Two Q fever outbreaks were described in 2000 and 2014 involving 50 safari travelers [30] and 31 individuals in a small village in Rift Valley Province [31], respectively. Six deaths were reported in the latter outbreak. One of five Q fever cases diagnosed in 2008 among western travelers/tourists returning from tropics with fever was from Kenya [32]. A seroprevalence survey on banked sera of febrile patients treated in a rural clinic in western Kenya recorded seropositivity of 30.9 , with $3 \%$ of patients who had been diagnosed with acute lower respiratory infections (ALRI) being found to have acute Q fever [17]. A study by Cook et al. [33] reported C. burnetii seroprevalence of $4.5 \%$ in abattoir workers in western Kenya while Mwololo et al. [34] found $26.8 \%$ seropositivity in individuals in Bura district where mixed crop farming and pastoralism are practiced. The findings in these studies were recently presented at international conferences [33, 34].

\section{Coxiella burnetii infection in animals (Coxiellosis)}

Serological surveys conducted in 1956 revealed 33.8, 7.4 and $75 \%$ (3 of 4 dogs) seroprevalence in sheep, cattle and dogs, respectively from Central province, while

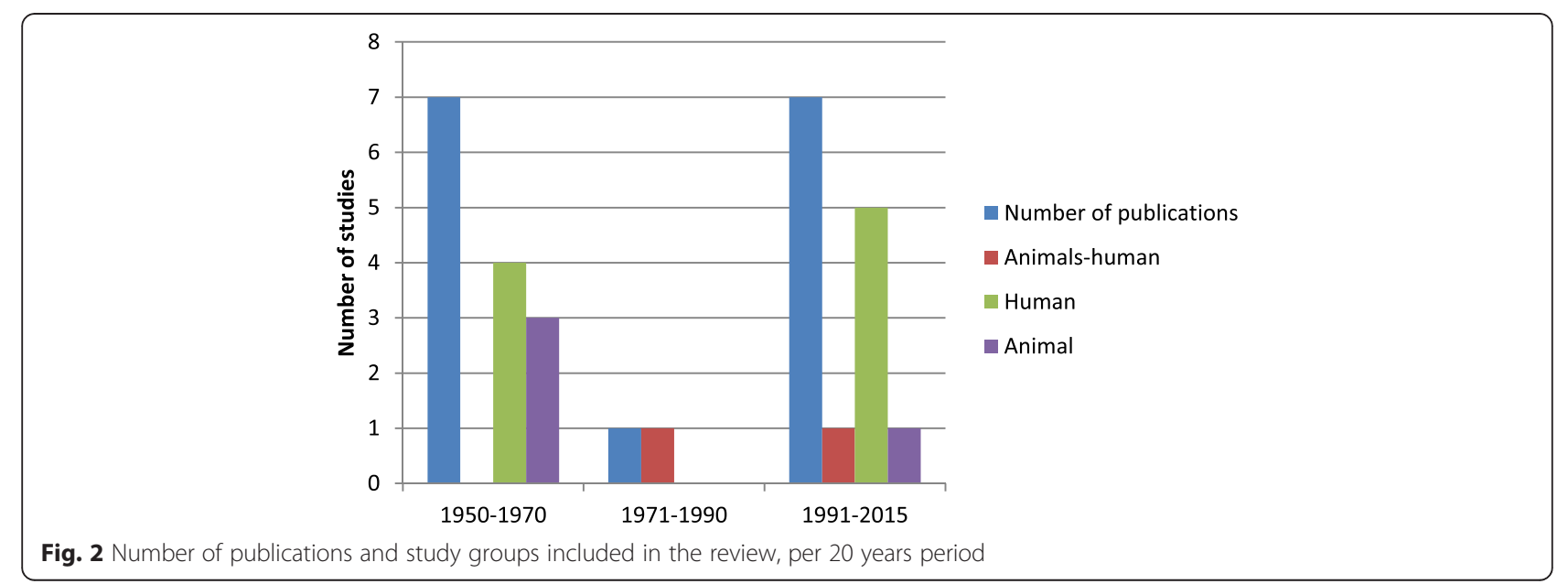


North Rift region showed seroprevalence of 20 and $51.1 \%$ in camels and cattle respectively [35, 38]. Brotherston and Cook (1956) found a higher C. burnetii seroprevalence $(51.1 \%)$ in cattle from the same region in the same year [28]. The study of Heisch et al. [36] found $2.6 \%$ of cattle and $6.7 \%$ sheep to be seropositive for C. burnetii in parts of Eastern province [36]. The study also showed a prevalence of about $13 \%$ in 12 different species of wild rodents. The bacteria were detected in 81 organ pools (brain or spleen) of seropositive Lemniscomys spp. A 1976 study using banked sera from domestic animals (cattle, sheep and goats) from five administrative provinces (Western, Rift Valley, Central, Eastern, and Coast) showed that the prevalence in each of the regions ranged from 10-42.5 \% [29]. Recently, Knobel et al. [17] reported high Coxiella seropositivity in cattle $(28.3 \%)$, goats $(30 \%)$, and sheep $(18.2 \%)$ in the western region [17]. A more recent study in mixed domestic animal-wildlife ranches of lower rift region found variation in seroprevalence among domestic animals; camels (46\%), goats (40\%) and sheep (20\%), respectively [37].

\section{Coxiella in ticks}

Two studies described the presence of Coxiella in ticks. In 1962, Heisch et al. isolated C. burnetii by inoculating guinea-pigs with samples of ticks obtained from rodents in Nairobi, Rift Valley, and Eastern Provinces [39]. The study by Knobel et al. [17] detected Coxiella DNA in $50 \%$ of tick pools obtained from domestic animals in Western Kenya. The highest prevalence was found in Haemaphysalis leachi [17].

\section{Risk factors}

The study by Mwololo et al. (2014) on possible risk factors for $\mathrm{Q}$ fever infections in humans, identified increased age and farming as risk factors for seropositivity [34], while Cook et al. (2014) identified alcohol intoxication status of abattoir workers at work and lack of appropriate protective clothing as risk factors for Coxiella infection [33].

\section{Q fever diagnosis}

Previous studies and reports in Kenya mainly utilized Complement Fixation Test (CFT) [26-29, 35-39] and only recently Enzyme-Linked Immunosorbent Assay (ELISA) [17, 31, 33, 34] and Immuno Fluorescence Assay (IFAT) [17] diagnostic assays were used to detect the presence of Coxiella antibodies in humans and animals. The study by Heisch et al. [39] demonstrated seroconversion of guinea pigs inoculated with ticks and organ pool samples obtained from wild rodents towards a range of rickettsial pathogens including Coxiella [39].
We found no study in which cell culture or PCR assays (that are widely considered as the gold standard for diagnosis for $\mathrm{Q}$ fever) were used.

\section{Q fever control programmes: One health approach}

The government of Kenya in realization of the need for concerted inter sectoral (one health) approach in control of zoonotic diseases, formed the Kenya Zoonotic Diseases Unit (ZDU) in 2011. This intergovernmental unit aimed to establish collaborative programmes for effective prevention of zoonotic diseases in Kenya. However, we found no study or reports describing $\mathrm{Q}$ fever vaccination or disease awareness/control programmes in Kenya during our searches. At the time of this review, the disease was neither a notifiable disease nor listed in the priority zoonotic diseases list for Kenya [31].

\section{Discussion}

The past surveys show strong evidence of Q fever exposure in animals and humans in all regions in which studies were conducted and the seroprevalence rates appear high. This is in contrast to the scarce literature available (Table 1). Though the first Q fever case was reported 63 years ago in Kenya [26, 35], only limited high quality epidemiologic studies utilizing randomly sampled human-animal populations for Coxiella have been conducted. Available studies were mainly retrospective using archived samples either submitted to reference laboratories or collected in hospitals for other diseases diagnosis resulting in sampling bias. We found no descriptions of official national disease surveillance and reporting or control programs in the published literatures. This knowledge gap highlights the need for more representative epidemiological studies in the country to elucidate the exact disease burden and pathogen transmission dynamics involved. The high seroprevalence of human antibodies against Coxiella antigens in the previous studies (3-35.8\%) suggests that cases are often misdiagnosed and/or unrecognized potentially leading to wrong patient management. This is a great challenge also in many sub-Saharan Africa countries where other tropical fevers such as malaria, typhoid, rotavirus and pneumonia are endemic. These infections present with similar symptoms making their diagnosis difficult leading to systematic under-reporting in the human health system [40, 41]. Studies in neighboring countries have reported comparable Coxiella seropositivity in humans, i.e., in Tanzania (3.9-20.3 \%) [13, 19, 42], in Ethiopia (6.5\%) [43], and in Sudan (10 \%) [44].

$\mathrm{Q}$ fever is widely classified as an occupational disease for those who have close contact with animals or their products. Lack of appropriate personal protective clothing, present or past residing in a farm are reported 
Table 1 Reviewed studies and reports of C. burnetii infection in humans and animals in Kenya

\begin{tabular}{|c|c|c|c|c|c|}
\hline Study year & Region & Species & Prevalence/reactors & Inclusion criteria & Reference \\
\hline 1952 & Central & Human & 1 case & Case study & Harris, B.P \\
\hline 1955 & Rift valley & Human & 13 cases & Case study & Craddock, A.L. and J. Gear \\
\hline \multirow[t]{2}{*}{1956} & Central & Human & 4 cases & Case study & Brotherston, J.C. and E.R. Cooke \\
\hline & Rift valley & Cattle & 20 of 35 cases & & \\
\hline \multirow[t]{4}{*}{1956} & Central & Cattle & $7.4 \%$ & Retrospective epidemiological study & Brown, R.D \\
\hline & Central & Goats & $33.8 \%$ & & Vogel L.C et al. \\
\hline & Rift valley & Camel & $20 \%$ & & \\
\hline & Central & Dogs & (3 of 4 ) cases & Case study & \\
\hline 1960 & Multiple regions & Rodent & $13 \%$ & Seroepidemiological study & Heisch, R.B. \\
\hline \multirow[t]{3}{*}{1962} & Eastern & Cattle & $2.6 \%$ & Seroepidemiological study & Heisch, R.B., et al. \\
\hline & Eastern & Sheep & $6.7 \%$ & & \\
\hline & Multiple regions & Ticks & $2.3 \%$ & & \\
\hline \multirow[t]{11}{*}{1976} & Western & Human & $45.7 \%$ & Retrospective epidemiological study & Vanek, E. and B. Thimm \\
\hline & & Cattle & $32.9 \%$ & & \\
\hline & & Goats & 30 & & \\
\hline & Rift valley & Human & $20.3 \%$ & & \\
\hline & & Cattle & $22.9 \%$ & & \\
\hline & Central & Human & $12 \%$ & & \\
\hline & & Cattle & $10 \%$ & & \\
\hline & Eastern & Human & $41 \%$ & & \\
\hline & & Cattle & $31.9 \%$ & & \\
\hline & Coast & Human & $50.4 \%$ & & \\
\hline & & Cattle & $42.5 \%$ & & \\
\hline 2000 & Rift valley & Human & $8 \%$ & Outbreak investigation & Potasman, l., et al. \\
\hline 2008 & Unknown & Human & 1 case & Case study & Ta, T., et al. \\
\hline \multirow[t]{6}{*}{2013} & Western & Human & $3 \%$ & Epidemiological study & Knobel, D.L., et al. \\
\hline & & Human & $30.9 \%$ & Retrospective epidemiological study & \\
\hline & & Cattle & $28.3 \%$ & & \\
\hline & & Goats & $30 \%$ & & \\
\hline & & Sheep & $18.2 \%$ & & \\
\hline & & Ticks & $50 \%$ & & \\
\hline \multirow[t]{3}{*}{2014} & Rift valley & Camel & $46 \%$ & Epidemiological study & DePuy, W., et al. \\
\hline & & Goats & $40 \%$ & & \\
\hline & & Cattle & $20 \%$ & & \\
\hline 2014 & Coast & Human & $26.8 \%$ & Seroepidemiological study & Mwololo D. K et al. \\
\hline 2014 & Western & Human & $4.5 \%$ & Seroepidemiological study & Cook, E.A. et al. \\
\hline 2014 & Rift valley & Human & $54.8 \%$ & Outbreak investigation & ZDU, Kenya \\
\hline
\end{tabular}

to increase ones odds for Coxiella seropositivity $[9,12]$. Farming, alcohol intoxication status of abattoir workers and lack of appropriate protective clothing during work were associated with seropositivity in Kenya [33, 34]. However, high quality data related to $\mathrm{Q}$ fever awareness or underlying social-economic or cultural factors predisposing humans to $C$ burnetii infection are lacking. No studies were found on populations considered at high risk of infection such as veterinarians, retail butchers, pastoralist communities, and mixed livestock-crop production farmers. A study in Egypt on high risk groups reported high seropositivity (16 and $22 \%$ ) in populations living in close contact with animals and those living in rural establishment [45]. In contrast, a study in Chad 
found low seropositivity (1\%) in similar high risk groups [46]. A study in Tanzania demonstrated an association between Q fever onset and dry season [18]. Our review did not identify investigations on how the pathogen cycles are potentially embedded in livestock production and management systems in the economically and ecologically heterogeneous regions of Kenya.

We identified no study in human populations from northern eastern and upper eastern regions of Kenya but the available animal reports from similar populations in north rift regions revealed high exposure rates of $51.1 \%$ and $20 \%$ in cattle and camel, respectively (Fig. 3) [29, 35]. Epidemiological studies are needed in these high risk regions of Kenya because the communities in these regions practice mixed livestock ranching-and-wildlife conservancy systems and predominantly individual livestock-based pastoralism with high rates of livestock-wildlife interaction. Seroprevalence of C. burnetii of 7.4-51.1\% in cattle, $20-46 \%$ in goats, $6.7-20 \%$ in sheep, 20 and $46 \%$ in camel and $13 \%$ in rodents have been reported [18, 29, 35, 37, 38]. We found no distinct variation in C. burnetii infections among the animal species and the different administrative provinces. However, there were seemingly higher infections (28.2-57.1\%) reported in livestock from arid and semiarid ecoregions of Rift Valley, Coast, Western and Eastern provinces when compared to Central and Nairobi. Though the precise reason for this variation is not clear, it is possible that specific local variation in prevalence exist based on the differences in animal husbandry practices, human and livestock density patterns and the differences

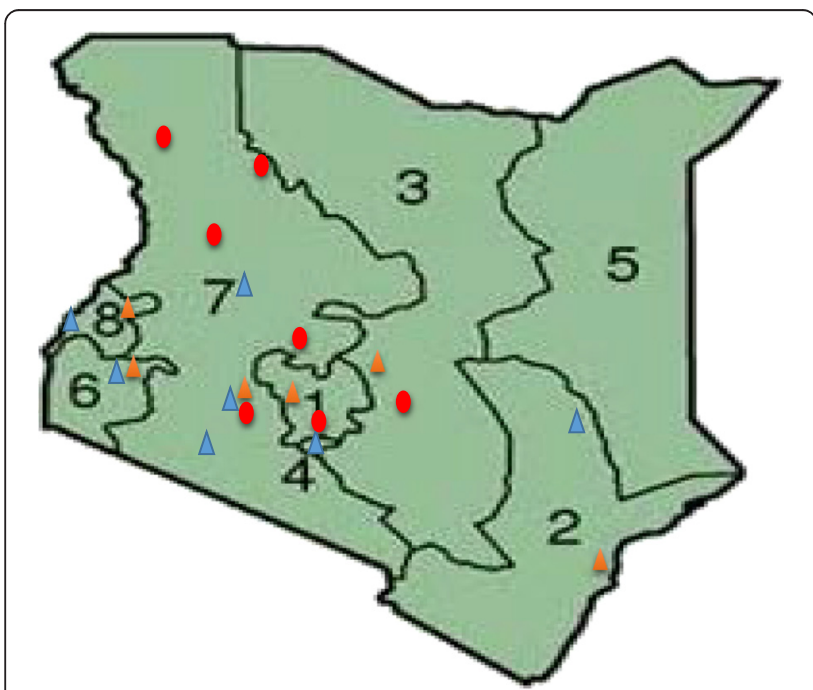

Fig. 3 Map of Kenya showing eight administrative provinces (numbered) and spatial distribution of the previous studies. Key: Blue triangle: human studies; yellow triangle: linked human and animal studies; red dots: animal studies; 1: Central; 2: Coast; 3: Eastern; 4: Nairobi; 5: North eastern; 6: Nyanza; 7: Rift valley; 8: Western in livestock infection in each of the ecoregions. Therefore, if no appropriate control strategies are implemented, the infected animals may continue to serve as reservoirs and source of infection to the uninfected animals and humans. Moreover, data on other common domestic animals in Kenya such as pigs, donkeys, and cats are not available. Therefore, the role of these domestic animals or ruminant wildlife animals as reservoirs and transmission of Coxiella need to be investigated. Surveys in the neighboring countries have reported Coxiella seropositivity with similar ranges in domestic animals, i.e., in Tanzania (13.3\% cattle, $13.6 \%$ goats, $17.1 \%$ sheep) [42], Ethiopia ( $31.6 \%$ cattle, $54.2 \%$ goats, $90 \%$ camel) [47] and Sudan (24\% goats, $40.4 \%$ cattle, $53 \%$ goats, $62.5 \%$ sheep $[48,49]$. This epidemiologic status may be linked to the unregulated crossborder livestock movements through trade routes and nomadic movements between these countries in search of pasture and watering points that may allow the entry and spread of infected herds. These findings call for further research to elucidate the epidemiology of Q fever in linked animal and human populations in large representative surveys (within this african region) to enable assess the correlations of the disease incidence with agricultural production systems, geographical and climatic conditions and the animal husbandly practices.

Cell culture of Coxiella in a variety of culture media is considered as the gold standard for diagnosis for Q fever. However, the process is usually time consuming and difficult. Moreover, Coxiella is a highly hazardous pathogen whose isolation requires biosafety level 3 (BSL3) laboratory facilities because of its high infectivity potential [9]. As a result, this requires huge investments in terms of specialized skills and equipment. These are not affordable in many developing countries such as Kenya and thus previous epidemiological studies based on bacterial isolation have not been feasible. Recently, a cell-free laboratory culture medium whose composition mimics that of the host cells phagolysosome has been developed and it is undergoing evaluation and validation [2]. This discovery may therefore permit culture based epidemiological studies in resource limited settings such as Kenya in future. Detection of C. burnetii DNA in various samples by a range of Polymerase Chain Reaction (PCR) assays is progressively becoming available and is considered useful especially in the acute clinical stages of the illness when seroconversion is not sufficient to be detected by serological methods [50]. Similarly, the cost of the respective equipment and technical expertise makes it difficult for adoption for routine hospital based testing or to enable seroepidemiological research in many developing countries. Despite the availability of these diagnostic facilities in specialized and research laboratories in Kenya, Q fever diagnosis is still not considered during routine human and animals' disease 
diagnosis systems. This can be attributed to the fact that these facilities are located in major towns which are not readily accessible to the regional health care facilities. Efforts to establish a regional laboratory in at least each county with facilities for performing reliable serological assay such as ELISA or serum based real-time qPCR are highly recommended. This approach will shorten the time needed to gain a sensitive diagnosis in patients presenting with fever of unknown origin and enable appropriate management of the patients.

As shown for other countries, controlling of the disease in animals contributes significantly to the decreased incidence in humans [51]. Vaccination of animals against Q fever could therefore present an effective control method. Until now, several vaccines have been developed consisting of inactivated whole phase 1 bacteria. However, many were shown to be nonprotective and presented several limitations such as short term protection and the inability to distinguish between vaccinated and naturally infected animals. Currently, prevention of Q fever in some European countries includes animal vaccination with the non-fully licensed inactivated phase I vaccine, Coxevac (CEVA-Santé Animale, France), after a focus of $\mathrm{Q}$ fever has been determined [9]. Several different vaccines have been developed for use in humans. These are mainly composed of a live attenuated strain or subunit vaccines $[2,52]$. Despite demonstrating antigenicity and immunogenicity in many trials, humans develop severe reactions to the vaccinations making many of these vaccines effective to only individuals that have no previous exposures. This necessitates extensive screening before administration to having a direct impact on the final cost of the vaccine [53]. Presently, the considered effective vaccine is a formalin killed whole-cell vaccine (Qvax, CSL Limited, Australia) that is licensed for use in Australia, especially in high risk occupational groups. The availability of the vaccines present a great challenge in most of the developing countries and is currently not performed in Kenya.

\section{Limitations of the data}

Lack of national level surveys and individual studies not being representative might lead to inappropriate estimates of $\mathrm{Q}$ fever prevalence. Also, the authors of the included studies have not taken into account the confounding bias and this may affect the true estimate.

\section{Conclusions}

This is the first review of Q fever disease in animals and humans in Kenya. The findings from past literatures strongly suggest that $C$. burnetii infections are common in both humans and animals. Social-economic factors and lack of disease surveillance/control programmes present a significant risk of pathogen persistence and transmission in human and animal populations. More research is needed to elucidate the epidemiology of $\mathrm{Q}$ fever in linked animal and human populations in order to understand in greater details the human and animal exposure in different ecoregions and the correlations with disease incidence in different agricultural production systems. As with all zoonotic diseases, close collaboration between veterinary and medical authorities (One Health) both on national and regional levels is necessary in order to establish an integrated health surveillance and prevention/control programs for the disease in Kenya.

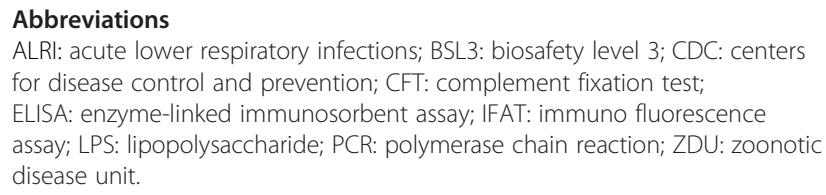

\section{Authors' contributions}

$\mathrm{NJ}$ designed the study, did the data extraction, analysis and interpretation and drafted the initial manuscript. $\mathrm{HK}$ and $\mathrm{NH}$ contributed in the conceptualization of the study and review, analysis and interpretation. PM and HR contributed in review, analysis and interpretation. All authors read and approved the final manuscript as submitted.

\section{Acknowledgements}

We would like to thank the DAAD (German Academic Exchange Service) for financial support of NJ grant no. A/12/97862. The funder had no role in study design, data collection and analysis, decision to publish, or preparation of the manuscript. This paper is published with the permission of Director KEMRI.

\section{Author details}

${ }^{1}$ Institute of Bacterial Infections and Zoonosis, Friedrich-Loeffler-Institut, 07743 Jena, Germany. ${ }^{2}$ Center for Infectious Diseases and Infection Control, Jena University Hospital, 07740 Jena, Germany. ${ }^{3}$ Centre for Microbiology Research (CMR), Kenya Medical Research Institute, P. O. Box 19464-00202, Nairobi, Kenya. ${ }^{4}$ Center for Molecular Biomedicine, Institute for Molecular Cell Biology, Friedrich Schiller University Jena, 07745 Jena, Germany.

Received: 25 August 2015 Accepted: 6 March 2016 Published online: 05 April 2016

\section{References}

1. De Lange MM, Schimmer B, Vellema P, Hautvast UL, Schneeberger PM, Van Duijnhoven YT. Coxiella burnetii seroprevalence and risk factors in sheep farmers and farm residents in The Netherlands. Epidemiol Infect. 2014;142(6):1231-44.

2. Maurin M, Raoult D. Q fever. Clin Microb Rev. 1999;12:518-53.

3. Mege JL, Maurin M, Capo C, Raoult D. Coxiella burnetii. the 'query' fever bacterium. A model of immune subversion by a strictly intracellular microorganism. FEMS microb Rev. 1997;19(4):209-17.

4. Khalili M, Shahabi-Nejad N, Golchin M. Q fever serology in febrile patients in southeast Iran. Trans R Soc Trop Med Hyg. 2010;104(9):623-4.

5. Slavin G. 'Q'fever: the domestic animal as a source of infection for man. Vet Rec. 1952;64.

6. Benenson A, Tigertt W. Studies on Q fever in man. Trans Assoc Am Physicians. 1955;69:98-104

7. Sidi-Boumedine K, Rousset E, Henning K, Ziller M, Niemczuck K, Roest H, et al. Development of harmonised schemes for the monitoring and reporting of Q-fever in animals in the European Union, EFSA Scientific report. 2010. p. $1-48$ 
8. Bernard H, Brockmann SO, Kleinkauf N, Klinc C, Wagner-Wiening C, Stark K et al. High seroprevalence of Coxiella burnetii antibodies in veterinarians associated with cattle obstetrics, Bavaria, 2009. Vector Borne Zoonotic Dis. 2012;12(7):552-7.

9. Porter SR, Czaplicki G, Mainil J, Guattéo R, Saegerman C. Q Fever: current state of knowledge and perspectives of research of a neglected zoonosis. Int J Microbiol. 2011. doi:10.1155/2011/248418.

10. Schimmer B, Lenferink A, Schneeberger $P$, Aangenend $H$, Vellema $P$, Hautvast J, et al. Seroprevalence and risk factors for Coxiella burnetii (Q fever) seropositivity in dairy goat farmers' households in The Netherlands, 2009-2010. PLoS One. 2012;7(7), e42364.

11. Honarmand H. Q Fever: An old but still a poorly understood disease. Interdiscip Perspect Infect Dis. 2012. doi:10.1155/2012/131932.

12. de Rooij MM, Schimmer B, Versteeg B, Schneeberger P, Berends BR, Heederik D, et al. Risk factors of Coxiella burnetii ( $Q$ fever) seropositivity in veterinary medicine students. PLoS One. 2012;7(2), e32108.

13. Crump JA, Morrissey AB, Nicholson WL, Massung RF, Stoddard RA, Galloway $\mathrm{RL}$, et al. Etiology of severe non-malaria febrile illness in Northern Tanzania: a prospective cohort study. PLoS Negl Trop Dis. 2013;7(7), e2324.

14. Vanderburg S, Rubach MP, Halliday JE, Cleaveland S, Reddy EA, Crump JA. Epidemiology of Coxiella burnetii infection in Africa: a OneHealth systematic review. PLoS Negl Trop Dis. 2014;8(4), e2787.

15. Epelboin L, Chesnais C, Boullé C, Drogoul A-S, Raoult D, Djossou F, et al. Q fever pneumonia in French Guiana: prevalence, risk factors, and prognostic score. Clin Infect Dis. 2012;55(1):67-74.

16. Manock SR, Jacobsen KH, de Bravo NB, Russell KL, Negrete M, Olson JG, et al. Etiology of acute undifferentiated febrile illness in the Amazon basin of Ecuador. Am J Trop Med Hyg. 2009;81(1):146-51.

17. Knobel DL, Maina AN, Cutler SJ, Ogola E, Feikin DR, Junghae M, et al. Coxiella burnetii in humans, domestic ruminants, and ticks in rural western Kenya. Am J Trop Med Hyg. 2013;88(3):513-8.

18. Prabhu M, Nicholson WL, Roche AJ, Kersh GJ, Fitzpatrick KA, Oliver LD, et al. $\mathrm{Q}$ fever, spotted fever group, and typhus group rickettsioses among hospitalized febrile patients in northern Tanzania. Clin Infect Dis. 2011;53(4):e8-15.

19. Makungu C, Gwakisa PS. Community knowledge and attitudes and health workers' practices regarding non-malaria febrile illnesses in eastern Tanzania. PLoS Negl Trop Dis. 2014;8(5), e2896.

20. To H, Htwe KK, Kako N, Kim HJ, Yamaguchi T, Fukushi H, et al. Prevalence of Coxiella burnetii infection in dairy cattle with reproductive disorders. J Vet Med Sci. 1998;60(7):859-61.

21. Angelakis E, Million M, D'Amato F, Rouli L, Richet $H$, Stein A, et al. Q fever and pregnancy: disease, prevention, and strain specificity. Eur J Clin Microbiol Infect Dis. 2013;32(3):361-8.

22. Beaudeau F, Guatteo R, Seegers H. Excretion of Coxiella burnetii by dairy cows: consequences for disease screening and control. Épidémiol et Santé Anim. 2006:49:1-4

23. Guatteo R, Beaudeau F, Berri M, Rodolakis A, Joly A, Seegers H. Shedding routes of Coxiella burnetii in dairy cows: implications for detection and control. Vet Res. 2006;37(6):827-33.

24. Fishbein DB, Raoult D. A cluster of Coxiella burnetii infections associated with exposure to vaccinated goats and their unpasteurized dairy products. Am J Trop Med Hyg. 1992;47(1):35-40.

25. Anderson A, Bijlmer H, Fournier PE, Graves S, Hartzell J, Kersh GJ, et al. Diagnosis and management of Q fever-United States, 2013: recommendations from CDC and the $\mathrm{Q}$ fever working group. MMWR Recomm Rep. 2013:62(RR-03):1-30.

26. Harris BP. Q-fever in Nairobi. East Afr Med J. 1952;29(4):128-30.

27. Craddock AL, Gear J. Q fever in Nakuru, Kenya. Lancet. 1955;269(6901):1167-9.

28. Brotherston JC, Cooke ER. Q fever in Kenya. East Afr Med J. 1956;33(4):125-30.

29. Vanek E, Thimm B. Q fever in Kenya. Serological investigations in man and domestic animals. East Afr Med J. 1976;53(12):678-84.

30. Potasman I, Rzotkiewicz S, Pick N, Keysary A. Outbreak of Q fever following a safari trip. Clin Infect Dis. 2000;30(1):214-5.

31. Kenya Zoonosis Diseases Unit. Q fever outbreak response, Baringo County, March 2014. 462 http://zdukenya.org/outbreaks/. Accessed 02 Jan. 2016.

32. Ta TH, Jimenez B, Navarro M, Meije Y, Gonzalez FJ, Lopez-Velez R. Q Fever in returned febrile travelers. J travel med. 2008:15(2):126-9.

33. Cook EG, William A, Thomas LF, Bronsvoort BM, Kariuki S, Fèvre EM. Slaughterhouse zoonoses: Leptospirosis and Q fever in Kenya. Amsterdam: International One Health Congress; 2014.
34. Mwololo DK, Wanyoike PM, Bett B. Seroprevalence and risk factors of Coxiella burnetii (Q fever) infection among humans in Bura irrigation scheme. Tana River County: Biennial Scientific Conference and exhibition of the Faculty of Veterinary Medicine; 2014.

35. Brown RD. Q fever-veterinary aspects. East Afr Med J. 1956;33(11):441-5.

36. Heisch RB. The isolation of Rickettsia burnetii from Lemniscomys sp. in Kenya. East Afr Med J. 1960;37:104.

37. DePuy W, Benka V, Massey A, Deem S, Kinnaird M, O'Brien T, et al. Q Fever risk across a dynamic, Heterogeneous Landscape in Laikipia County, Kenya. EcoHealth. 2014;11(3):429-33.

38. Vogel LC, Muller AS, Odingo RS. Health and Diseases in Kenya. 1st ed. East African Literature Bureau Nairobi: 1974.

39. Heisch RB, Grainger WE, Harvey AEC, Lister G. Feral aspects of Rickettsial infections in Kenya. Trans R Soc Trop Med Hyg. 1962;56(4):272-82.

40. Amexo M, Tolhurst R, Barnish G, Bates I. Malaria misdiagnosis: effects on the poor and vulnerable. Lancet. 2004;364(9448):1896-8.

41. Kallander K, Nsungwa-Sabiiti J, Peterson S. Symptom overlap for malaria and pneumonia-policy implications for home management strategies. Acta Trop. 2004;90(2):211-4.

42. Hummel PH. Incidence in Tanzania of CF antibody to Coxiella burnetii in sera from man, cattle, sheep, goats and game. Vet Rec. 1976;98(25):501-5.

43. Abebe A. Prevalence of $Q$ fever infection in the Addis Ababa abattoir. Ethiopian med J. 1990;28(3):119-22.

44. Botros BA, Soliman AK, Salib AW, Olson J, Hibbs RG, Williams JC, et al. Coxiella burnetii antibody prevalences among human populations in north-east Africa determined by enzyme immunoassay. Am J Trop Med Hyg. 1995:98(3):173-8.

45. Nahed G, Abdel-moein A. Seroprevalence of Coxiella burnetii antibodies among farm animals and human contacts in Egypt. J Am Sci. 2012:8:619-21.

46. Schelling E, Diguimbaye C, Daoud S, Nicolet J, Boerlin P, Tanner M, et al. Brucellosis and Q-fever seroprevalences of nomadic pastoralists and their livestock in Chad. Prev Vet Med. 2003;61(4):279-93.

47. Gumi B, Firdessa R, Yamuah L, Sori T, Tolosa T, Aseffa A, et al. Seroprevalence of Brucellosis and Q-Fever in Southeast Ethiopian Pastoral Livestock. J Vet Sci Med Diagn. 2013; 2(1). doi:10.4172/2325-9590.1000109.

48. Hussien M, ElFahal A, Enan K, Taha K, Mohammed M, Salih D, et al. Seroprevalence of Q fever in Goats of the Sudan. Vet World. 2012;5:394-7.

49. Reinthaler FF, Mascher F, Sixl W, Arbesser $\mathrm{CH}$. Incidence of Q fever among cattle, sheep and goats in the Upper Nile province in southern Sudan. Vet Rec. 1988;122(6):137.

50. Fournier PE, Raoult D. Comparison of PCR and serology assays for early diagnosis of acute Q fever. J Clin Microbiol. 2003;41(11):5094-8.

51. Jiang X, Baldwin CL. Effects of cytokines on intracellular growth of Brucella abortus. Infect Immun. 1993;61(1):124-34.

52. Ascher MS, Berman MA, Ruppanner R. Initial clinical and immunologic evaluation of a new phase IQ fever vaccine and skin test in humans. J Infect Dis. 1983;148(2):214-22.

53. O'Neill T, Sargeant J, Poljak Z. The Effectiveness of Coxiella burnetii vaccines in occupationally exposed populations: a systematic review and metaAnalysis. Zoonoses Public HIth. 2014;61(2):81-96.

\section{Submit your next manuscript to BioMed Central and we will help you at every step:}

- We accept pre-submission inquiries

- Our selector tool helps you to find the most relevant journal

- We provide round the clock customer support

- Convenient online submission

- Thorough peer review

- Inclusion in PubMed and all major indexing services

- Maximum visibility for your research

Submit your manuscript at www.biomedcentral.com/submit 